\title{
PENGARUH MUTASI, PROMOSI JABATAN DAN KEPUASAN KERJA TERHADAP PRESTASI KERJA PEGAWAI KEMENTERIAN SOSIAL REPUBLIK INDONESIA
}

\author{
Irawati Kusuma Dirja ${ }^{1)}$ \\ 1) Mahasiswa Fakultas Ekonomi Universitas Darma Persada \\ Ismail Razak ${ }^{2)}$ \\ 2) Dosen Program Studi Manajemen FE UNKRIS \\ Alamat: Kampus UNKRIS, Jatiwaringin Jakarta Timur \\ Email: ismailrazak.zain8@gmail.com
}

\begin{abstract}
The aim of this study was to analize the effect of mutation, job promotion, and job satisfaction on the achievement of employee of the Ministry of Social Affairs of the Republic of Indonesia. Primary data was obtained from employee of the Ministry of Social Affairs of the Republic of Indonesia through admission filling of questionnaire by using scale of Likert. Data analysis technique used in this research is simple linear regression and multiple linear regression. The results of this study indicated that mutation, job promotion, and job satisfaction positively and significant influenced the achievement of employee of the Ministry of Social Affairs of the Republic of Indonesia..
\end{abstract}

Keywords: Mutation, job promotion, job satisfaction, and achievement of employee.

\section{PENDAHULUAN}

Bagi organisasi, prestasi kerja pegawai menjadi syarat penting bagi tercapainya tujuan organisasi secara efektif dan efisien (Adha dan Qamariah, 2020). Salah satu faktor yang mendukung untuk peningkatan prestasi kerja adalah promosi dan mutasi jabatan (Abdullah, 2017). Secara teoritis, apabila setiap pegawai memiliki akses atas promosi berdasarkan asas keadilan dan objektivitas, pegawai akan terdorong untuk lebih giat bekerja, bersemangat, berdisiplin, dan berprestasi kerja (Indrawan, 2015). Kebijakan mutasi dapat menjadi salah satu solusi untuk meningkatkan prestasi kerja karyawan (Wati, et al, 2020). Selain itu, sering ada rasa kurang puas dari pegawai yang lain, akhirnya berakibat pada menurunnya prestasi kerja (Sudiantoro, 2014).

Hasil penelitian ini merupakan pengembangan hasil penelitian yang dilakukan oleh Judas (2013), Nurdin, et al (2015), Indrawan (2015), Utami, et al (2017), Saputri dan Suryalena (2018), dan Wati, et al (2020) mengenai sumber daya manusia yang menjelaskan hubungan kausalitas antara mutasi dan promosi jabatan dengan prestasi pegawai. Hubungan kausalitas antara kepuasan kerja dikembangkan dari hasil penelitian yang dilakukan oleh Yuniastuti (2011).

Kementerian Sosial Republik Indonesia merupakan instansi pemerintah yang mempunyai tugas menyelenggarakan dan membidangi urusan dalam negeri untuk membantu presiden dalam penyelenggaraan di bidang sosial. Program mutasi di Kementerian Sosial Republik Indonesia sering dilakukan, di mana terdapat dua jenis mutasi yang lazim dilakukan mutasi vertical dan horizontal. Mutasi vertikal dilakukan untuk mengisi kekosongan 
jabatan yang lebih tinggi dari posisi jabatan sebelumnya, sedangkan mutasi horizontal dilakukan untuk mengisi kekosongan jabatan yang setingkat. Biasanya mutasi dilakukan di Kementerian Sosial Republik Indonesia minimal selama 2 tahun sekali. Selain mutasi, promosi jabatan sering dilakukan di Kementerian Sosial Republik Indonesia. Biasanya promosi jabatan dilakukan apabila seorang pegawai telah menduduki jabatan minimal selama 2 tahun dan melaksanakan pekerjaan dengan prestasi kerja yang baik. Kementerian Sosial Republik Indonesia juga mengupayakan kepuasan kerja pegawai melalui peningkatan kesejahteraan, menciptakan kondisi kerja yang lebih baik, dan menjalin hubungan yang baik sesama rekan kerja pegawai untuk meningkatkan prestasi kerja.

Mutasi, promosi jabatan dan kepuasan kerja ditujukan untuk meningkatkan prestasi kerja pegawai Kementerian Sosial Republik Indonesia. Mutasi, promosi jabatan dan kepuasan kerja bertujuan agar pegawai dapat bekerja secara optimal, sehingga menghasilkan prestasi kerja pegawai yang lebih baik. Namun demikian, dalam pelaksanaan mutasi, promosi jabatan, dan peningkatan kepuasan kerja untuk meningkatkan prestasi kerja tidaklah mudah, banyak kendala yang dihadapi. Oleh karena itu, tujuan penelitian ini adalah untuk menganalisis pengaruh mutasi, promosi jabatan, dan kepuasan kerja terhadap prestasi kerja pegawai Kementerian Sosial Republik Indonesia.

\section{LANDASAN TEORI}

\section{Prestasi Kerja}

Prestasi kerja adalah hasil kerja secara kualitas dan kuantitas yang dicapai oleh seorang pegawai dalam melaksanakan tugasnya sesuai dengan tanggung jawab yang diberikan kepadanya (Prabu, 2004 dalam Judas,
2013). Menurut Byars dan Rue, prestasi sebagai tingkat kecakapan seseorang pada tugas-tugas yang mencakup pekerjaan (Sutrisno, 2014). Prestasi kerja adalah proses melalui mana organisasiorganisasi mengevaluasi atau menilai prestasi kerja karyawan (Rivai, 2011 dalam Nurdin, et al, 2015). Hasibuan (2012), prestasi kerja adalah suatu hasil kerja yang dicapai seseorang dalam melaksanakan tugas-tugas yang dibebankan kepadanya yang didasarkan atas kecakapatan dan kesunguhan serta waktu (Magdalena dan Rulyati, 2019).

Indikator prestasi kerja terdiri atas; 1) Hasil kerja, yaitu tingkat kuantitas dan kualitas yang telah dihasilkan, dan sejauhmana pengawasan yang dilakukan. 2) Pengetahuan pekerjaan, yaitu tingkat pengetahuan yang terkait dengan tugas pekerjaan yang akan berpengaruh langsung terhadap kuantitas dan kualitas dari hasil kerja. 3) Inisiatif, yaitu tingkat inisiatif selama melaksanakan tugas, khususnya dalam hal penanganan masalah-masalah yang timbul. 4) Kecekatan mental, yaitu tingkat kemampuan dan kecepatan dalam hal menerima instruksi kerja dan menyesuaikan dengan cara kerja serta situasi kerja yang ada. 5) Sikap, yaitu tingkat semangat kerja dan sikap positif dalam melaksanakan pekerjaanpositif dalam melaksanakan pekerjaan. 6) Disiplin waktu dan absensi, yaitu tingkat ketepatan waktu dan tingkat kehadiran yaitu tingkat ketepatan waktu dan tingkat kehadiran.

\section{Mutasi}

Menurut Sastrohadiwiryo (2002), mutasi adalah kegiatan tenaga kerja yang berhubungan dengan proses pemindahan fungsi, tanggung jawab, dan status ketenagakerjaan tenaga kerja ke situasi tertentu dengan tujuan agar tenaga kerja yang bersangkutan memperolah kepuasan kerja yang mendalam dan dapat memberikan prestasi kerja yang 
semaksimal mungkin kepada organisasi (Kadarisman, 2012 dan Indrawan, 2015). Menurut Daryanto (2013), mutasi adalah suatu kegiatan rutin dari suatu perusahaan untuk dapat melaksanakan prinsip "the right man on the right place", sedangkan menurut Hanggraeni (2012), mutasi adalah pemindahan dari posisi yang baru tapi memiliki kedudukan, tanggung jawab, dan jumlah remunerasi yang sama. Mutasi adalah kegiatan memindahkan tenaga kerja dari satu tempat tenaga kerja ke tempat kerja lain (Sudiantoro, 2014). Hasibuan (2016), mutasi adalah suatu perubahan posisi atau jabatan atau tempat atau pekerjaan yang dilakukan baik secara horizontal maupun vertical di dalam suatu organisasi (Wati, et al, 2020).

Indikator mutasi terdiri atas pengalaman, pengetahuan, kebutuhan, kecakapan, dan tanggung jawab. Pengalaman adalah masa kerja, tingkat loyalitas, pengetahuan pekerja, dan ruang lingkup suatu pekerjaan. Pengetahuan adalah kemampuan dalam menyelesaikan tugas, mudah mengoperasikan peralatan pekerjaan. Kebutuhan adalah kekosongan karyawan, dan permintaan karyawan. Kecakapan adalah tingkat pemahaman prosedur kerja, tingkat pengetahuan yang mendukung pelaksanaan kerja, ketrampilan dalam berkomunikasi antar sesama pekerja. Tanggung jawab adalah keseriusan dalam bekerja, ketaatan pada aturan organisasi, dan berdedikasi pada aturan organisasi.

\section{Promosi Jabatan}

Menurut Saydam, istilah promosi berasal dari promotion, yang berarti peningkatan (Kadarisman, 2012). Dalam manajemen sumber daya manusia, yang dimaksud dengan promosi adalah perubahan pekerjaan atau status jabatan pegawai dari tingkat yang rendah ke tingkat yang lebih tinggi. Perubahan tersebut biasanya diikuti dengan perubahan tanggung jawab, wewenang, kompensasi, status sosial, dan fasilitas yang didapat pegawai tersebut.

Promosi dapat diartikan sebagai proses perubahan dari satu pekerjaan ke pekerjaan lain dalam hirarki wewenang dan tanggung jawab yang lebih tinggi daripada dengan wewenang dan tanggung jawab yang telah diberikan kepada tenga kerja pada waktu sebelumnya (Sastrohadiwiryo, 2002 dalam Indrawan, 2015). Menurut Badriyah (2015), promosi adalah penghargaan dengan kenaikan jabatan dalam organisasi atau instansi, baik dalam pemerintahan maupun non-pemerintahan (swasta), sedangkan menurut Salidi, promosi adalah perpindahan dari suatu jabatan ke jabatan lain yang mempunyai status dan tanggung jawab yang lebih tinggi (Yusuf, 2015). Menurut Sedarmayanti (2017), promosi jabatan adalah kegiatan perpindahan pegawai dari satu jabatan ke jabatan lain yang mempunyai status serta tanggung jawab yang lebih tinggi (Wati, et al, 2020).

Menurut Yusuf (2015), indikator promosi jabatan terdiri atas; 1). Kepercayaan; Kepercayaan mengenai kejujuran, kemampuan, dan kecakapan karyawan bersangkutan dalam melaksanakan tugas-tugas dengan baik pada jabatan tersebut. Karyawan akan dipromosikan jika dapat menunjukkan kejujuran, kemampuan, dan kecakapan dalam memangku jabatan. 2). Keadilan; Keadilan merupakan penilaian harus jujur, objektif, dan tidak pilih kasih. Karyawan yang mempunyai peringkat terbaik hendaknya mendapatkan kesempatan pertama untuk dipromosikan tanpa melihat suku, agama, golongan, dan keturunan. Promosi yang berasaskan keadilan akan menjadi alat motivasi bagi karyawan lain untuk meningkatkan prestasi. 3). Formasi; Promosi karyawan hanya dilakukan jika ada formasi jabatan yang lowong. Untuk itu harus ada uraian pekerjaan (job description) yang akan dilaksanakan karyawan. Jadi promosi 
disesuaikan dengan formasi jabatan yang ada di dalam perusahaan.

\section{Kepuasan Kerja}

Hasibuan (2000), kepuasan kerja adalah sikap emosional yang menyenangkan dan mencitai pekerjaannya (Minar, 2009). Menurut Priansa (2014), kepuasan kerja merupakan perasaan pegawai terhadap pekerjaan, apakah senang atau tidak senang sebagai hasil interaksi pegawai dengan lingkungan pekerjaan atau sebagai presepsi sikap mental, juga sebagai hasil penilaian pegawai terhadap pekerjaan mencerminkan sikap dan perilaku dalam bekerja. Robbins (2015), mengartikan kepuasan kerja adalah suatu sikap umum terhadap pekerjaan seseorang sebagai perbedaan antara banyaknya ganjaran yang diterima pekerja dengan banyaknya ganjaran yang diyakini seharusnya diterima.

Robbins dan Judge, indikator kepuasan kerja terdiri atas; 1). Pekerjaan itu sendiri, yaitu merupakan sumber utama kepuasan, dimana pekerjaan tersebut memberikan tugas yang menarik, kesempatan untuk belajar, kesempatan untuk menerima tanggung jawab dan kemajuan untuk karyawan. 2). Gaji atau upah, yaitu merupakan faktor multidimensi dalam kepuasan kerja. Sejumlah upah yang diterima karyawan menjadi penilaian untuk kepuasan, dimana hal ini bisa dipandang sebagai hal yang dianggap pantas dan layak. 3). Kondisi kerja, yaitu kondisi kerja yang nyaman dan mendukung pekerja untuk dapat menjalankan aktivitas dengan baik. 4). Promosi, yaitu kesempatan untuk berkembang secara intelektual dan memperluas keahlian menjadi dasar perhatian penting untuk maju dalam organisasi, sehingga menciptakan kepuasan. 5). Rekan kerja, yaitu rekan kerja yang kooperatif merupakan sumber kepuasan kerja yang paling sederhana. 6). Pengawasan, yaitu merupakan kemampuan penyedia untuk memberikan bantuan teknis dan dukungan perilaku.

\section{Hipotesis}

1. Mutasi berpengaruh positif dan signifikan terhadap prestasi kerja pegawai Kementerian Sosial Republik Indonesia.

2. Promosi jabatan berpengaruh positif dan signifikan terhadap prestasi kerja pegawai Kementerian Sosial Republik Indonesia.

3. Kepuasan kerja berpengaruh positif dan signifikan terhadap. prestasi kerja pegawai Kementerian Sosial Republik Indonesia

4. Mutasi, promosi jabatan, dan kepuasan kerja berpengaruh positif dan signifikan terhadap prestasi kerja pegawai Kementerian Sosial Republik Indonesia.

\section{METODE PENELITIAN}

\section{Metode Pengumpulan Data}

Jenis data yang dipergunakan dalam penelitian ini adalah data subyek, yaitu berupa opini, sikap, dan pengalaman dari pegawai Biro Organisasi dan Kepegawaian Sekretariat Jenderal Kementerian Sosial Republik Indonesia. Sumber data yang digunakan dalam penelitian ini adalah data primer, yaitu data yang diperoleh langsung melalui penyebaran kuesioner dengan menggunakan skala Likert kepada pegawai Biro Organisasi dan Kepegawaian Sekretariat Jenderal Kementerian Sosial Republik Indonesia sebagai responden. Skala Likert yang digunakan terdiri atas; sangat setuju dengan bobot 4 , setuju dengan bobot 3 , tidak setuju dengan bobot 2 , dan sangat tidak setuju dengan bobot 1 .

Populasi dalam penelitian ini adalah jumlah pegawai Biro Organisasi dan Kepegawaian Sekretariat Jenderal Kementerian Sosial Republik Indonesia 
sebanyak 110 orang. Pemilihan sampel berdasarkan sampel jenuh, yaitu sampel yang digunakan dalam penelitian ini adalah sejumlah populasi sebanyak 110 orang sebagai responden. Penelitian dilaksanakan selama kurun waktu tiga bulan, yaitu dari bulan April hingga bulan Juni 2019 di Kantor Kementerian Sosial Republik Indonesia, Jakarta.

\section{Metode Analisis Data}

\section{Analisis regresi linear sederhana}

Untuk menganalisis pengaruh mutasi terhadap prestasi kerja pegawai Kementerian Sosial Republik Indonesia digunakan analisis regresi linear sederhana yaitu sebagai berikut:

$Y=\alpha_{1}+\beta_{1} X_{1}$

Untuk menganalisis pengaruh promosi jabatan terhadap prestasi kerja pegawai Kementerian Sosial Republik Indonesia digunakan analisis regresi linear sederhana yaitu sebagai berikut:

$\mathrm{Y}=\alpha_{2}+\beta_{2} \mathrm{X}_{2}$

Untuk menganalisis pengaruh kepuasan kerja terhadap prestasi kerja pegawai Kementerian Sosial Republik Indonesia digunakan analisis regresi linear sederhana yaitu sebagai berikut:

$Y=\alpha_{3}+\beta_{3} X_{3}$

\section{Analisis regresi linear berganda}

Untuk menganalisis pengaruh mutasi, promosi jabatan, dan kepuasan kerja terhadap prestasi kerja pegawai Kementerian Sosial Republik Indonesia digunakan analisis regresi linear berganda, yaitu sebagai berikut:

$$
\begin{aligned}
& \mathrm{Y}=\alpha_{4}+\beta_{1} \mathrm{X}_{1}+\beta_{2} \mathrm{X}_{2}+\beta_{3} \mathrm{X}_{3} \\
& \text { dimana } \\
& \mathrm{Y}=\text { Prestasi kerja } \\
& \mathrm{X}_{1}=\text { Mutasi } \\
& \mathrm{X}_{2}=\text { Promosi jabatan } \\
& \mathrm{X}_{3}=\text { Kepuasan kerja } \\
& \mathrm{a}_{\mathrm{i}}=\text { Konstanta }(\mathrm{i}=1,2,3,4) \\
& \mathrm{b}_{\mathrm{i}}=\text { Koeisinen Regresi }(\mathrm{i}=1,2,3)
\end{aligned}
$$

\section{HASIL DAN PEMBAHASAN}

\section{Hasil Penelitian}

\section{Uji Validitas dan Reliabilitas}

Berdasarkan hasil uji validitas dan uji reliabilitas dari variabel yang diteliti, yaitu mutasi, promosi jabatan, kepuasan kerja dan prestasi kerja menunjukkan bahwa setiap butir pertanyaan yang diajukan kepada responden dinyatakan valid dan reliabel. Hal ini berarti bahwa responden telah memahami setiap pertanyaan yang diajukan dan responden konsisten pada butir pertanyaan yang ditentukan.

\section{Hasil Uji Hipotesis}

Hasil penelitian menunjukkan bahwa mutasi, promosi jabatan, dan kepuasan kerja berpengaruh positif dan signifikan terhadap prestasi kerja. Besarnya pengaruh mutasi, promosi jabatan, dan kepuasan kerja terhadap prestasi kerja dapat dilihat pada Tabel-1. 
Tabel-1: Uji Kausalitas Variabel Penelitian dan Uji Hipotesis

\begin{tabular}{lcccc}
\hline \multirow{2}{*}{$\begin{array}{c}\text { Variabel } \\
\text { Independen }\end{array}$} & \multicolumn{4}{c}{ Koefisien Regresi } \\
\cline { 2 - 5 } Konstanta & Hipotesis-1 & Hipotesis-2 & Hipotesis-3 & Hipotesis-4 \\
\hline \multirow{2}{*}{ Mutasi } & $\begin{array}{c}1,670^{* * *} \\
(0,000)\end{array}$ & $\begin{array}{c}1,394^{* * *} \\
(0,000)\end{array}$ & $\begin{array}{c}0,951^{* * *} \\
(0,000)\end{array}$ & $\begin{array}{c}0,561^{* * *} \\
(0,000)\end{array}$ \\
\hline \multirow{2}{*}{ Promosi jabatan } & $0.408^{* * *}$ & - & - & $0,130^{* * *}$ \\
& $(0,000)$ & & $0,000)$ \\
\hline \multirow{2}{*}{ Kepuasan kerja } & - & $0,538^{* * *}$ & - & $0,379 * * *$ \\
& - & - & $0,651^{* * *}$ & $0,282^{* * *}$ \\
\hline F-hitung & - & - & $(0,000)$ & $(0,000)$ \\
\hline $\mathrm{R}^{2}$ & 0,141 & 0,565 & - & $63,885 * * *$ \\
\hline
\end{tabular}

Keterangan: p-value $<\mathbf{0 , 0 5}$

Hasil penelitian menunjukkan bahwa estimasi koefisien regresi secara parsial kepuasan kerja terhadap prestasi kerja sebesar 0,651 lebih besar jika dibandingkan dengan estimasi koefisien regresi mutasi dan promosi jabatan terhadap prestasi kerja, yaitu masingmasing sebesar 0.408 dan 0,538 . Selanjutnya, estimasi koefisien regresi secara bersama-sama promosi jabatan terhadap prestasi kerja, yaitu sebesar 0,379lebih besar jika dibandingkan dengan estimasi koefisien regresi mutasi dan kepuasan kerja terhadap prestasi kerja, yaitu masing-masing sebesar 0,130 dan 0,282. Hasil penelitian menunjukkan bahwa mutasi, promosi jabatan, dan kepuasan kerja sangat berpengaruh terhadap prestasi kerja baik secara parsial maupun secara bersama-sama.

a. Hipotesis pertama

Mutasi berpengaruh positif dan signifikan terhadap prestasi kerja, sesuai dengan hipotesis. Dengan demikian, hipotesis pertama teruji dan hasil penelitian membuktikan bahwa terdapat hubungan kausalitas antara mutasi dengan prestasi kerja. Koefisien determinasi $\left(\mathrm{R}^{2}\right)$ sebesar 0,141, artinya mutasi memberikan konstribusi kepada prestasi kerja sebesar $14,1 \%$, sedangkan sisanya sebesar $85,9 \%$ disumbangkan oleh faktor-faktor lain, seperti promosi jabatan, kepuasan kerja dan berbagai faktor lain. Koefisien regresi mutasi bertanda positip, artinya jika mutasi dilakukan sesuai prosedur, maka prestasi kerja diduga akan meningkat atau sebaliknya.

b. Hipotesis kedua

Promosi jabatan berpengaruh positif dan signifikan terhadap prestasi kerja, sesuai dengan hipotesis. Dengan demikian, hipotesis kedua teruji dan hasil penelitian membuktikan bahwa terdapat hubungan kausalitas antara promosi jabatan dengan prestasi kerja. Koefisien determinasi $\left(\mathrm{R}^{2}\right)$ sebesar 0,565, artinya promosi jabatan memberikan konstribusi kepada prestasi kerja sebesar 56,5\%, sedangkan sisanya sebesar $43,5 \%$ disumbangkan oleh faktor-faktor lain, seperti mutasi, kepuasan kerja dan berbagai faktor lain. Koefisien regresi promosi jabatan bertanda positip, artinya jika promosi jabatan dilakukan sesuai prosedur, maka 
prestasi kerja diduga akan meningkat atau sebaliknya.

c. Hipotesis ketiga

Kepuasan kerja berpengaruh positif dan signifikan terhadap prestasi kerja, sesuai dengan hipotesis. Dengan demikian, hipotesis ketiga teruji dan hasil penelitian membuktikan bahwa terdapat hubungan kausalitas antara kepuasan kerja dengan prestasi kerja. Koefisien determinasi $\left(\mathrm{R}^{2}\right)$ sebesar 0,464, artinya kepuasan kerja memberikan konstribusi kepada prestasi kerja sebesar $46,4 \%$, sedangkan sisanya sebesar $53,6 \%$ disumbangkan oleh faktor-faktor lain, seperti mutasi, promosi jabatan dan berbagai faktor lain. Koefisien regresi kepuasan kerja bertanda positip, artinya jika kepuasan kerja meningkat, maka prestasi kerja diduga akan meningkat atau sebaliknya.

d. Hipotesis keempat

Nilai F-hitung sebesar 63,885 , artinya secara bersamasama, mutasi, promosi jabatan, dan kepuasan kerja berpengaruh signifikan terhadap prestasi kerja. Koefisien determinasi $\left(\mathrm{R}^{2}\right)$ sebesar 0,644 , yang artinya mutasi, promosi jabatan, dan kepuasan kerja secara bersama-sama memberikan kontribusi kepada prestasi kerja sebesar $64,4 \%$, sedangkan sisanya sebesar $35,6 \%$ disumbangkan oleh faktor lain, seperti lingkungan kerja, motivasi kerja, kompensasi, kompetensi, dan berbagai faktor lain.

Koefisien regresi mutasi bertanda positif, artinya jika mutasi dilakukan sesuai prosedur, maka prestasi kerja diduga akan meningkat atau sebaliknya dengan asumsi promosi jabatan dan kepuasan kerja tidak berubah.
Koefisien regresi promosi jabatan bertanda positif, artinya jika promosi jabatan dilakukan sesuai prosedur, maka prestasi kerja diduga akan meningkat atau sebaliknya dengan asumsi mutasi dan kepuasan kerja tidak berubah. Koefisien regresi kepuasan kerja bertanda positif, artinya jika kepuasan kerja meningkat, maka prestasi kerja diduga akan meningkat atau sebaliknya dengan asumsi mutasi dan promosi jabatan tidak berubah.

\section{Pembahasan}

\section{Pengaruh Mutasi terhadap Prestasi Kerja}

Pelaksanaan mutasi dilakukan sesuai prosedur dapat mendukung peningkatan prestasi kerja pegawai Kementerian Sosial Republik Indonesia, hal ini dikarenakan semakin diperhatikan tanggung jawab dalam pelaksanaan mutasi akan meningkatkan prestasi kerja, sehingga pegawai berusaha memaksimalkan hasil pekerjaan dan tingkat kehadiran pegawai meningkat. Hasil penelitian ini mendukung hasil penelitian yang dilakukan oleh Sudiantoro (2014), Saputri dan Suryalena (2018), Wati, et al (2020) yang telah membuktikan bahwa mutasi dapat mendorong peningkatan prestasi kerja.

\section{Pengaruh Promosi Jabatan} terhadap Prestasi Kerja

Pelaksanaan promosi jabatan dilakukan sesuai prosedur dapat mendukung peningkatan prestasi kerja pegawai Kementerian Sosial Republik Indonesia, hal ini dikarenakan semakin banyak formasi promosi jabatan akan meningkatkan prestasi kerja, sehingga pegawai berusaha 
memaksimalkan hasil pekerjaan dan tingkat kehadiran pegawai meningkat. Hasil penelitian ini sesuai dan memperkuat hasil penelitian terdahulu yang dilakukan oleh Judas (2013), Prabowo (2017), Saputri dan Suryalena (2018), Magdalena dan Rulyati (2019), Wati, et al (2020) yang telah membuktikan bahwa promosi jabatan dapat meningkatkan prestasi kerja.

3. Pengaruh Kepuasan Kerja terhadap Prestasi Kerja

Peningkatan kepuasan kerja dapat mendukung peningkatan prestasi kerja pegawai Kementerian Sosial Republik Indonesia, hal ini dikarenakan kondisi kerja semakin baik, hubungan kerja antar rekan kerja semakin harminis, dan gaji yang sesuai akan meningkatkan prestasi kerja, sehingga pegawai berusaha memaksimalkan hasil pekerjaan, dan tingkat kehadiran pegawai meningkat. Hasil penelitian ini mendukung hasil penelitian yang dilakukan oleh Yuniastuti (2011), dan Rusydiati (2017) yang telah membuktikan bahwa kepuasan kerja dapat mendorong peningkatan prestasi kerja.

4. Pengaruh Mutasi, Promosi Jabatan, dan Kepuasan Kerja terhadap Prestasi Kerja

Pelaksanaan mutasi dan promosi jabatan dilakukan sesuai prosedur, serta peningkatan kepuasan kerja diduga dapat mendukung peningkatan prestasi kerja pegawai Kementerian Sosial Republik Indonesia, hal ini dikarenakan semakin diperhatikan pelaksanaan mutasi, semakin banyak formasi promosi jabatan, lingkungan kerja semakin baik, kesempatan berkembang, dan gaji yang sesuai diduga akan meningkatkan prestasi kerja, sehingga pegawai berusaha memaksimalkan hasil pekerjaan dan tingkat kehadiran pegawai meningkat. Hasil penelitian ini mendukung hasil penelitian yang dilakukan oleh Judas (2013), Prabowo (2017), Saputri dan Suryalena (2018) yang telah membuktikan bahwa mutasi dan promosi jabatan secara bersamasama dapat meningkatkan prestasi kerja.

\section{KESIMPULAN DAN SARAN}

Kesimpulan

1. Mutasi mendorong peningkatan prestasi kerja pegawai Kementerian Sosial Republik Indonesia.

2. Promosi jabatan mendorong peningkatan prestasi kerja pegawai Kementerian Sosial Republik Indonesia.

3. Kepuasan kerja mendorong peningkatan prestasi kerja pegawai Kementerian Sosial Republik Indonesia.

4. Mutasi, promosi jabatan, dan kepuasan kerja secara bersama-sama mendorong peningkatan prestasi kerja pegawai Kementerian Sosial Republik Indonesia.

\section{Saran}

1. Perlu dipertimbangkan agar mutasi melalui peningkatan pengalaman, pengetahuan, kebutuhan, kecakapan, dan tanggung jawab lebih diperhatikan lagi dalam mendorong peningkatan prestasi kerja pegawai Kementerian Sosial Republik Indonesia.

2. Perlu dipertimbangkan agar promosi jabatan melalui peningkatan kepercayaan, keadilan, dan formasi lebih diperhatikan lagi dalam mendorong peningkatan prestasi 
kerja pegawai Kementerian Sosial Republik Indonesia.

3. Bagi penelitian selanjutnya disarankan untuk menempatkan variabel kepuasan kerja sebagai variabel yang memediasi hubungan korelasional antara variabel mutasi dan promosi jabatan dengan prestasi kerja pegawai.

\section{DAFTAR PUSTAKA}

Abdullah. 2017. Pengaruh Promosi dan Mutasi terhadap Prestasi Kerja Pegawai pada Pengadilan Negeri Sigli. Jurnal Sosial Humaniora. Vol.1, No.2, hal. 109-119.

Adha, Wahyu, Maulid dan Qamariah, Nur. 2020. Analisis Pengaruh Pelatihan dan Promosi Kerja terhadap Prestasi Kerja pada Dinas Pertanian dan Peternakan Kabupaten Majene. Management Development and Applied Research Journal. Volume 2, Nomor 2, Edisi Juni 2020, hal:2230.

Ariani, Darmastuti., Utami, Hamidah, Nayati, dan Susilo, Heru. 2013. Pengaruh Kepuasan Kerja dan Motivasi Kerja terhadap Prestasi kerja Karyawan (Studi pada PT. Inti Luhur Fuja Abadi, Pasuruan). Jurnal Administrasi Busnis (JAB), Vol.1, No.1, April 2013, hal:123131.

Badriya, Mila. 2015. Manajemen Sumber Daya Manusia. Bandung. Pustaka Setia.

Ela, Suparinah. 2018. Pengaruh Mutasi dan Promosi Jabatan terhadap Kinerja karyawan pada PT. Waru Kaltim Plantation di Penajam Paser Utara. Jurnal Administrasi Bisnis. Vol.6, No.2, hal. 425-438.

Indrawan, Isa, Muhammad. 2015. Pengaruh Promosi Jabatan dan Mutasi terhadap Prestasi kerja
Pegawai PT. Bank Mandiri (Persero) Cabang Ahmad Yani Medan. Jurnal Ilmiah Integritas. Vol.1, No.3, 3 Oktober 2015.

Judas, Agneta. 2013. Mutasi dan Promosi Jabatan Pengaruhnya terhadap Prestasi Kerja Pegawai pada Kanwil Ditjen Kekayaan Negara Suluttenggo dan Maluku Utara. Jurnal EMBA, Vol.1, No.4, hal.1219-1228.

Kadarisman. 2012. Manajemen Pengembangan Sumber Daya Manusia. Jakarta, Rajawali Pers.

Magdalena, Betty, dan Rulyati, Okta. 2019. Pengaruh Promosi Jabatan terhadap Kepuasan Kerja Melalui Prestasi Kerja sebagai Variabel Intervening pada Karyawan TVRI Lampung. Jurnal Bisnis Darmajaya. Vol.05, No.02, Juli 2019, hal.80-89.

Mangkunegara, Anwar Prabu. 2013. Manajemen Sumber Daya Manusia. Bandung. Remaja Rosdakarya.

Minar, Demsi. 2009. Pengaruh Sistem Penggajian, Pengembangan Karir, dan Promosi terhadap Kepuasan Kerja Karyawan. Jurnal Computech \& Bisnis. Vol.3, No.3, Juni 2009, hal.43-56.

Nurdin., Yunus, Mukhlis., dan Chan, Syafrudin. 2015. Pengaruh Penempatan, Mutasi, dan Promosi terhadap Prestasi kerja serta Dampaknya terhadap Kinerja Pegawai Sekretariat Daerah Aceh. Jurnal Manajemen. Vol.4, No.2, Mei 2015, hal.221-228.

Patras, Desty., Murni, Sri, dan Jan, Arrazi, B.H. 2017. Pengaruh Kepuasan kerja, Lingkungan Kerja, dan Pemberian Insentif terhadap Prestasi Kerja Karyawan pada PT. Pegadaian (Persero) Kantor Wilayah V Manado. 
Jurnal EMBA. Vol.5, No.2, Juni 2017, hal:1978-1988.

Rusydiati. 2017. Kepuasan Kerja Guru terhadap Prestasi Kerja Guru dalam meningkatkan Mutu Pendidikan di Madrasah. Studia Didaktika: Jurnal Ilmiah Pendidikan, Vol.11, No.1, Juni 2017, hal. 45-54.

Saputri, Diah, Mustika, Rani., dan Suryalena. 2018. Pengaruh Mutasi dan Promosi Jabatan terhadap Prestasi Kerja (Studi pada Pegawai PT. Silver Silk Tour \& Travel, Pekanbaru). JOM Fisip, Vol.5, Edisi II, Juli - Desember 2018, hal:1-11.

Sudiantoro, Sugeng. 2014. Pengaruh Mutasi Karyawan terhadap Prestasi kerja pada Badan Pemeriksa Keuangan (BPK) Perwakilan Provinsi DI Yogyakarta. JBTI. Vo.5, No.2, Oktober 2014, hal. 273-287.

Sutrisno. Edy. 2017. Manajemen Sumber Daya Manusia. Jakarta. Kencana Prenada Media Group.

Surata, Made, I dan Paramarta, Arya, Wayan. 2015. Pengaruh Kebijakan Mutasi dan Promosi Jabatan terhadap Kepuasan Kerja dan Prestasi Kerja Pegawai pada Bagian Administrasi Umum dan Keuangan di Politeknik Negeri Bali. Jurnal Sosial Humaniora. Vol.5, No.2, Juli 2015.
Utami, Rizqi, Dwi, Yudho, Poniran, dan Meilina, Restin. 2017. Pengaruh Pelatihan Kerja, Promosi jabatan, dan Mutasi Jabatan terhadap Prestasi Kerja Karyawan Bank Jatim Cabang Nganjuk. SimkiEconomic. Vol.1, No.12, 2017.

Wati, Dahlia., Kusuma, Merta., dan Arianto, Tezar. 2020. Pengaruh Pengalaman Kerja, Promosi Jabatan, dan Mutasi terhadap Prestasi Kerja Karyawan. Jurnal Entrepreneur dan Manajemen Sain. Vol.1, No.1, Januari 2020.

Yuniastuti, Rina, Milyati. 2011. Pengaruh Kepuasan Kerja terhadap Prestasi Kerja Karyawan pada CV. Organik Argo System di Bandar Lampung. Jurnal Manajemen dan Bisnis, Vol.1, No.2, April 2011, hal:199-210. 
